\title{
Making Surveys Count: Enhancing the Rigor of Survey-Based Research in Medical Toxicology
}

\author{
Gillian A. Beauchamp ${ }^{1} \cdot$ Jeanmarie Perrone ${ }^{2}$
}

Received: 1 June 2016 / Accepted: 10 June 2016 / Published online: 24 June 2016

(C) American College of Medical Toxicology 2016

Survey-based studies in medicine gather important information on an individual or institutional level about demographics, practice patterns, knowledge, experience, attitudes, and behaviors that may otherwise be difficult to observe [1-3]. The often cited National Survey on Drug use and Health (NSDUH), which is sponsored by the Substance Abuse and Mental Health Services Administration (SAMHSA) provides national data on substance abuse in the United States by surveying a random selection of households based on address [4]. The National Institute on Drug Abuse (NIDA) has been conducting the annual 'Monitoring the Future' survey of drug use and attitudes among 8th, 10th, and 12th graders since 1975 - an effort that continues to shape research, education, and prevention in substance abuse [5].

Surveys may be used as a research strategy in both quantitative and qualitative studies and may provide initial data for hypothesis testing or to inform subsequent study design [2]. A 2013 survey of the New England Journal of Medicine's physician readership found that $78 \%$ of respondents supported the use of medical marijuana in certain circumstances, sparking debate in the medical community, and revealing the urgent need for further research in this area [6]. Advantages of survey-based studies include obtaining data within a short

Gillian A. Beauchamp

beauchamp.gillian@gmail.com

1 Department of Emergency Medicine and the Oregon Poison Center, Oregon Health and Science University, Campus Services Building 559, 3181 SW Sam Jackson Park Road, Portland, OR 97239, USA

2 Department of Emergency Medicine, Division of Medical Toxicology, University of Pennsylvania, Philadelphia, PA, USA time frame, relatively low cost, and results based on 'realworld' observations [2]. Disadvantages include the challenge of obtaining an adequate response rate, the possibility of data skewing due to non-responders, and difficulty determining the significance of data if an inadequate survey tool or inappropriate survey administration is used [2].

As the discipline of medical toxicology matures and strives to promote excellence in research, toxicologists should aspire to adhere to rigorous methodology in the design, implementation, and reporting of survey-based data. In order to translate the time and effort spent designing a survey into a substantive publication, authors should consider using study design guidelines available through publishers, academic institutions, and the research literature. The publication of high-quality survey studies has potential to shape all aspects of medical toxicology, in as much as such studies are accurate, generalizable, timely, and balance inherent methodological limitations with thoughtful study design.

Important steps in designing a survey-based study include formulating a research question and determining if a survey is the best tool to address the construct of interest [7]. A literature review will help to determine if a previously validated survey tool exists [3]. When a survey is the best tool to answer a specific research question, the chosen survey design and approaches to administration should address both reliability and validity to ensure the study is conducted effectively and appropriately $[8,9]$. Reliability is the extent to which both the survey instrument, and administration is reproducible [3]. Validity is the extent to which the survey measures the hypothesized concept $[1,3]$. Factors that affect reliability and validity include ambiguous survey questions; the use of cognitively burdensome and error-prone verbal answer scales; inadequate survey response options; survey results that do not address the research question; inadequate response rate; failure to adequately characterize non-responders; and a study 
design that is poorly described and therefore difficult to reproduce $[3,10,11]$.

In order to collect evidence surrounding reliability and variability, authors should elicit expert reviews and content validation. Before the study is undertaken, a pilot study of potential respondents with characteristics similar to the intended study sample should be used to inform revision of the survey tool $[3,7]$. Researchers should obtain Institutional Review Board (IRB) approval for all survey studies and should engage each subject in the informed consent process by providing a description of potential benefits and harms, as well the ultimate fate of study data $[2,12]$. Although participation in a survey study seems to be low risk, many studies have shown how participating in a survey can actually change one's perceptions or behavior in unintended ways and can also create "social desirability bias" or the desire of the subject to provide responses that will be accepted and liked [13]. Thus, IRB approval is needed. Further, researchers should choose study subjects carefully so that they represent the study population of interest [10]. Sample selection should be tailored to both study objectives, and available resources, and can include approaches such as random sampling among a larger population of interest (such as using a 'lottery' to select 50 toxicologists to survey from a national membership organization); sampling from heterogeneous clusters of potential subjects (such as choosing one toxicologist to survey from each geographic region within a country); and convenience sampling (such as interviewing toxicologists on call for poison centers during a specific time frame) [8]. Maximization of response rate should be undertaken while ensuring the ethical treatment of subjects [12]. Approaches may include personalized pre-notification, reminder notifications, the use of simple and accessible survey tools, and the judicious use of incentives [14]. Appropriate sample size should be determined while keeping any resource limitations in mind [2].

Since survey research is designed to collect a 'snapshot' of information from a representative sample, a delay in data reporting limits the ability to estimate the parameters of interest within a specific time frame, condition, or event [2]. Components of the implementation process that affect study results include selection and recruitment of subjects, approach to survey administration, incentives and reminders, and statistical analysis of data. Each step in the survey study design and implementation process should be outlined in the manuscript 'Methods' section, such that the study could be easily replicated [7, 12]. Authors should provide clear details on study design and outcomes to allow the reader to make an assessment of reliability and validity [7].

Medical toxicologists with research questions that are well answered with a survey should strive for a study design that maximizes validity, reproducibility, protection of subjects, and timeliness of data reporting. JMT frequently receives manuscripts describing survey-based investigations. Careful forethought in the design phase of the study will maximize the quality of the data obtained. The use of guidelines in the preparation of survey-based studies will enhance standards in medical toxicology research by encouraging robust study design and supporting the development of valid, credible, and publishable studies.

Guidelines for the preparation of survey-based studies for JMT:

1. IRB approval must be obtained prior to initiating a survey-based study.

2. Authors should review the American Association for Public Opinion Research Guidelines prior to designing and implementing a survey-based study [12].

3. Survey studies must report response rate and should have an adequate response rate (generally at least $50 \%$ ) or should provide justification for why the response rate was lower.

4. Authors should characterize demographics of nonresponders to ensure that study validity is not challenged by responder bias. Where this is not feasible, authors should provide an explanation for why it was not possible to obtain this information and should note this as a limitation in the manuscript.

5. Authors should explicitly report when data were collected. Timely reporting of data (ideally within 1-2 years of data collection) is encouraged.

6. Authors should submit the survey instrument with the manuscript for reviewer consideration. The instrument may be published with the study if deemed appropriate and of value to the journal's readership.

\section{Compliance with Ethical Standards}

Conflicts of Interest The authors have no conflicts of interest to disclose.

Sources of Funding The authors have no sources of funding.

\section{References}

1. Thayer-Hart N, Schaeffer NC, Dykema J, Elver K, Stevenson J. Office of Quality Improvement, University of WisconsinMadison: Survey Fundamentals, A guide to designing and implementing surveys. University of Wisconsin System Board of Regents. 2010 . https://oqi.wisc. 
edu/resourcelibrary/uploads/resources/Survey_Guide.pdf. Accessed 1 June 2016.

2. Kelley K, Clark B, Brown V, Sitzia J. Good practice in the conduct and reporting of survey research. Int J Qual Healthcare. 2003;15(3):261-6.

3. Rickards G, Magee M, Artino Jr AR. You Can't fix by analysis what you've spoiled by design: developing survey instruments and collecting validity evidence. J Grad Med Educ. 2012;4(4):407-10.

4. The National Survey on Drug Use and Health (NSDUH), Substance Abuse and Mental Health Services Administration (SAMHSA), U.S. Department of health and Human Services (DHHS). 2016. https://nsduhweb.rti.org/respweb/homepage.cfm. Accessed 18 May 2016.

5. National Institutes of Health, National Institute on Drug Abuse (NIDA) Monitoring the Future (MTF) 2015 Survey Results. 2016. https://www.drugabuse.gov/related-topics/trendsstatistics/infographics/monitoring-future-2015-survey-results. Accessed 31 March 2016.

6. Adler JN, Colbert JA. Clinical decisions. Medicinal use of marijuana_polling results. N Engl J Med. 2013;368(22):e30.

7. Mello MJ, Merchant RC. Surveying emergency medicine. Acad Emerg Med. 2013;20(4):409-12.

8. Burns KEA, Duffett M, Kho ME, Meade MO, Adhikari NKJ, Sinuff T, Cook DJ. For the ACCADEMY group. A guide for the design and conduct of self-administered surveys of clinicians. CMAJ. 2008;179(3):245-52.

9. Sullivan GM. A primer on the validity of assessment instruments. J Grad Med Educ. 2011;3(2):119-20.
10. Visser PS, Krosnick JA, Lavrakas PJ. Survey Research. Stanford University. 2013. http://web.stanford. edu/dept/communication/faculty/krosnick/Survey_Research.pdf. Accessed 1 June 2016.

11. Artino AR, La Rochelle JS, Dezee KJ, Gehlbach H. Developing questionnaires for educational research: AMEE guide no. 87. Med Teach. 2014;36(6):463-74.

12. American Association for Public Opinion Research (AAPOR). Best practices for research. 2016. https://www.aapor.org/StandardsEthics/Best-Practices.aspx. Accessed 31 March 2016.

13. Pew Research Center. U.S. Survey Research. 2016. http://www. pewresearch.org/methodology/u-s-survey-research/questionnairedesign/. Accessed 1 June 2016.

14. Evaluation Research Team. Centers for Disease Control and Prevention. 2010. http://www.cdc. gov/healthyyouth/evaluation/pdf/brief21.pdf. Accessed 18 May 2016.

A Note from the Editor: This commentary was developed by a working group of members of the JMT editorial board.

The guidelines included in this commentary were discussed, revised, and agreed upon by our editorial board. 